\title{
APLICAÇÃO DE SPME (SOLID PHASE MICRO-EXTRACTION) NA ANÁLISE DE ÁGUAS POTÁVEIS DE TRÊS LOCALIDADES DO ESTADO DE SÃO PAULO
}

\author{
Antonio Luiz Pires Valente*, Fabio Augusto, Larisse Montero e Eduardo Carasek da Rocha \\ Instituto de Química - Unicamp - CP 6154 - 13083-970 - Campinas - SP \\ Janusz Pawliszyn \\ Department of Chemistry - University of Waterloo - Waterloo - Ontario - Canadá - N2L 3G1
}

Recebido em 17/7/97; aceito em 13/04/98

\begin{abstract}
APPLICATION OF SPME (SOLID PHASE MICRO-EXTRACTION) TO THE ANALYSIS OF DRINKABLE WATER FROM THREE LOCATIONS IN THE STATE OF SÃO PAULO. The technique of solid phase microextraction (SPME) was used for the extraction of halogenated contaminants of water samples from three cities of the State of São Paulo and the extracts were submitted to gas chromatographic analysis with electron capture detection (GC-ECD). In the samples of water collected at the city of São Paulo the detected level of trihalomethanes (THM) expressed as the sum of chloroform, dibromochloromethane and dichlorobromomethane, were higher than the permissible limit established by the Brazilian regulation. In the samples collected at the two other cities the level of any of the three THM remained below the sensitivity of the ECD.
\end{abstract}

Keywords: drinkable water; SPME; trihalomethanes.

\section{INTRODUÇÃO}

A técnica de microextração em fase sólida (SPME, do inglês "Solid Phase Micro-Extraction") tem sido extensamente investigada como uma alternativa simples, versátil e de baixo custo para a preparação de amostras para análise por cromatografia gasosa (CG). Entre os estudos relatados na literatura encontram-se os de análises dos THM a níveis de pg.L $\mathrm{L}^{-1}$, que são comparáveis a detecções obtidas com técnicas convencionais ${ }^{1}$. Devido às características da técnica de SPME, extração sem solvente ${ }^{2}$, transferência direta, imediata e simplificada dos analitos para o cromatógrafo gasoso ${ }^{2}$ e simplicidade de uso, tanto para amostragem no "headspace", quanto diretamente na matriz aquosa (desde que não exista suspensão de materiais que possam contaminar ou danificar a fibra $)^{3,4,5}$, no nosso grupo de pesquisa estamos investindo esforços para sua implementação. Os resultados reportados neste artigo fazem parte deste esforço e demonstram que a SPME pode ser usada nas análises de THM. Os resultados também evidenciam que estas análises da água potável não podem ser negligenciadas, porque a existência de THM acima de limites permissíveis é uma realidade.

\section{MATERIAIS E MÉTODOS}

Amostras. Coletadas em Campinas: quatro amostras de 1 $\mathrm{L}$, sendo duas coletadas de torneiras alimentadas diretamente da rede de distribuição e duas de torneiras alimentadas de reservatórios de edifícios residenciais, São Carlos: uma amostra de $1 \mathrm{~L}$, de torneira alimentada diretamente da rede e São Paulo-Interlagos: duas amostras de $1 \mathrm{~L}$, de torneira alimentada diretamente da rede. A uma das amostras de São Paulo foi adicionado $1 \mathrm{~g}$ de tiossulfato de sódio, para inibir, durante o transporte e estocagem, o efeito oxidante do cloro sobre o material orgânico 6 ; a segunda amostra foi deixada "tal-qual" até a análise.

SPME. Fibras recobertas com $100 \mu \mathrm{m}$ de PDMS (polidimethilsiloxano) e aplicador 5-7330 ("sample holder") para injetor split/splitless (Supelco Inc., Bellefonte - PA, USA).

Cromatografia. Cromatógrafo Autosystem XL (Perkin Elmer
Corp., Norwalk - CT, USA) equipado com Detector por Captura de Elétrons (DCE), injetor tipo split/splitless, interfaceado com microcomputador Gateway 2000 4DX-50V com software para cromatografia TurboChrom 4.0 (Perkin Elmer). Coluna DB- $1, \mathrm{~L}=25 \mathrm{~m}, \mathrm{~d}_{\mathrm{i}}=0,32 \mathrm{~mm}, \mathrm{~d}_{\mathrm{f}}=0,25 \mu \mathrm{m}$. Temperaturas: injetor $=265^{\circ} \mathrm{C}$, detector $=280^{\circ} \mathrm{C}$, coluna $=45^{\circ} \mathrm{C}$ por $2 \mathrm{~min}$. e aquecimento de $10^{\circ} \mathrm{C} \cdot \mathrm{min}^{-1}$ até $125^{\circ} \mathrm{C}$. Injeção no modo "splitless" durante a dessorção. Vazão do gás de arraste $\left(\mathrm{N}_{2}\right.$ super-sêco) $=2,0 \mathrm{ml} \cdot \mathrm{min}^{-1}$.

\section{Metodologia}

1) As amostras de água potável foram submetidas a SPMECG para inspeção e determinação do número de picos cromatográficos detectados.

2) Padrões de clorofórmio, dibromoclorobenzeno e dibromoclorometano foram injetados conjuntamente com as amostras para identificação tentativa destes analitos por coincidência ("spiking") dos tempos de retenção.

3) Curvas analíticas com 5 pontos foram construídas com injeções feitas a partir de extrações de soluções aquosas dos padrões, clorofórmio, dibromoclorometano, diclobromometano e bromofórmio, com concentrações nas faixas de, respectivamente, 52 a $520 \mu \mathrm{g} . \mathrm{L}^{-1}, 0,8$ a $32 \mu \mathrm{g} . \mathrm{L}^{-1}, 1,1$ a $44,4 \mu \mathrm{g} . \mathrm{L}^{-1}$ e 1,0 a $210 \mu \mathrm{g} . \mathrm{L}^{-1}$.

4) Padrões e amostras foram analisados por SPME/CGDCE pelo mesmo procedimento: $25 \mathrm{ml}$ de solução aquosa colocados em frascos de $40 \mathrm{ml}$, tampados com septos; agitação magnética controlada para formação de um vortex regular; posicionamento da fibra com PDMS no headspace (por introdução da agulha do aplicador no septo do frasco); extração por 10 minutos; retirada do aplicador e sua inserção no injetor do CG por 5 min. para dessorção dos analitos da fibra PDMS e análise por CG-DCE; limpeza da fibra por exposição por 5 minutos no injetor aquecido do CG - a monitoração de sinais durante as limpezas não indicou resíduos dos analitos na fibra.

5) Replicatas. Optou-se por analisar as amostras no mesmo dia de construção das curvas de calibração. Devido ao tempo total entre extração (10 min), dessorção e análise cromatográfica (15 min. ou mais, vide Fig. 1), adotaram-se os 
seguintes critérios: (a) pontos das curvas de calibração em duplicata, com triplicata quando as áreas cromatográficas entre as duplicatas diferiam em mais de $10 \%$; (b) amostras: todas em triplicata.

\section{RESULTADOS E DISCUSSÃO}

Na figura 1 são mostrados três cromatogramas obtidos nas análises; o cromatograma A é do material extraído de uma solução aquosa dos padrões de clorofórmio, dibromoclorometano, diclorobromometano e bromofórmio, o cromatograma B é de amostra de água potável da cidade de Campinas e o cromatograma $\mathrm{C}$ de amostra de água potável da cidade de São Paulo. No cromatograma $\mathrm{C}$ nota-se claramente a presença de clorofórmio, dibromoclorometano e diclorobromometano; no cromatograma B estes compostos não foram quantificados, pois suas concentrações ficaram abaixo do limite de detecção da técnica; pela mesma razão o bromofórmio não foi quantificado nos cromatogramas B e C. O pico que aparece entre $8 \mathrm{~min}$ e $8,5 \mathrm{~min}$ nos três cromatogramas não foi identificado. Os estudos não contemplaram avaliar a origem do bromofórmio, ela já foi atri-

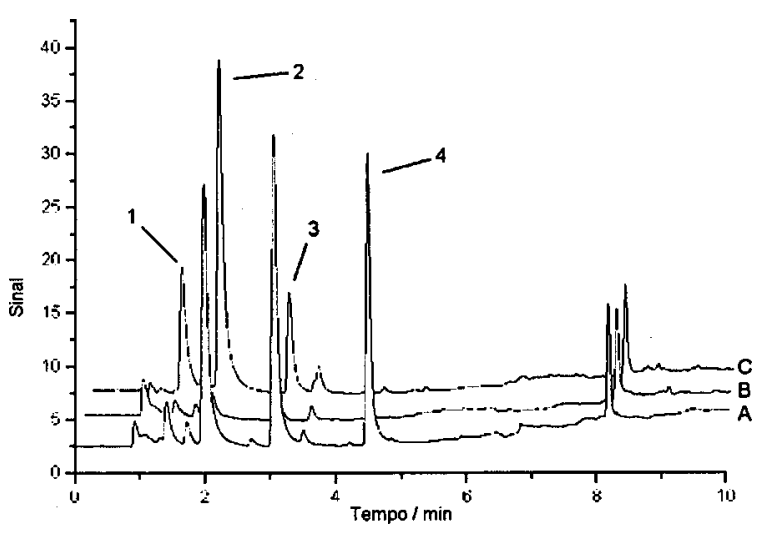

Figura 1. Cromatogramas obtidos por SPME-CG de solução aquosa padrão de THM (A), água potável de Campinas $(B)$ e água potável de São Paulo (C). Identificação dos picos: 1 - clorofórmio; 2 - bromodiclorometano; 3 - dibromoclorometano e 4 - bromofórmio. buída a reações secundárias, com brometo eventualmente presente na água ${ }^{7}$. Na tabela 1 estão relacionados os resultados obtidos na construção das curvas analíticas, com as quais foram interpoladas as concentrações dos três analitos, clorofórmio, dibromoclorometano e diclorobromometano, passíveis de quantificação nas amostras de águas potáveis analisadas. Como pode ser observado na tabela 1 , os valores dos desvios padrão relativos (dpr) obtidos para as três curvas analíticas encontram-se numa faixa de $0,05 \%$ a $6,4 \%$, o que é condizente com a espectativa de oscilação de resultados nas análises de amostras aquosas ${ }^{3}$. Portanto, pode-se concluir que a técnica de SPME permite repetibilidades adequadas para o trabalho em questão. Na tabela 2 estão relacionados os resultados obtidos com as amostras de águas potáveis. Nesta tabela pode-se observar que clorofórmio e diclorobromometano são os THM presentes em maiores concentrações, e que nas amostras em que foi adicionado tiossulfato de sódio as quantidades de THM são menores. Coerentemente, os resultados obtidos com as maiores quantidades extraídas (clorofórmio e diclorobromometano em água bruta - sem $\mathrm{Na}_{2} \mathrm{~S}_{2} \mathrm{O}_{3}$ ) são aqueles cujos dpr têm valores dentro da faixa de dpr das curvas de calibração.

\section{CONCLUSÕES}

Os resultados aqui apresentados demonstram que a técnica de SPME pode ser utilizada em análise de THM em água potável, com rapidez, pois a extração por 10 minutos, estabelecida como adequada em estudos anteriores ${ }^{8}$ permitiu o levantamento de dados quantitativos. Adicionalmente, opera-se com a facilidade analítica de amostragem do headspace, que mantém a representatividade das concentrações no meio aquoso ${ }^{9}$ e evita contaminações da fibra por particulado orgânico presente na amostra. Assim, e considerando o seu baixo custo, comparativamente com outras técnicas, a SPME pode viabilizar o cumprimento do dispositivo legal de $1992^{10}$, que determina a monitoração dos THM em águas potáveis - que pode não estar sendo realizada por vários laboratórios por falta de recursos orçamentários.

Foram observados maiores teores dos THM nas amostras aquosas em que não foi adicionado o tiossulfato de sódio, o que, como reportado na literatura, deve-se aos processos de halogenação de material orgânico existente na água da rede de distribuição municipal ${ }^{6}$.

O propósito deste trabalho foi avaliar a aplicabilidade da

Tabela 1. Dados sobre as curvas analíticas $A=a \cdot m+b^{\text {a }}$ utilizadas para quantificar os trialometanos ${ }^{\mathrm{b}}$.

\begin{tabular}{ccccc}
\hline Composto & $\mathrm{a} \times 10^{-3}$ & $\mathrm{~b}$ & $\mathrm{r}$ & $\Delta \mathrm{dpr}$ \\
\hline Clorofórmio & 14,3 & -58.0 & 0,999 & $0,6-3,0$ \\
Dibromoclorometano & 168 & 208 & 0,998 & $0,05-5,7$ \\
Diclorobromometano & 161 & -79.2 & 0,993 & $1,4-6,4$ \\
\hline
\end{tabular}

Notas:

a) $\mathrm{A}$ = área do pico cromatográfico, $\mathrm{m}=$ massa do analito, a e b = coeficientes angular e linear e $\mathrm{r}=$ coeficiente de correlação.

b) Quantificações dos Trialometanos na Tabela 2

c) $\Delta \mathrm{dpr}=$ faixa das estimativas dos desvios padrão relativos entre as extrações-quantificações para as cinco soluções padrão dos trialometanos; injeções em duplicata/triplicata conforme texto.

Tabela 2. Resultados obtidos com as amostras de água da cidade de São Paulo-Interlagos ${ }^{\mathrm{a}}$.

\begin{tabular}{|c|c|c|c|c|c|c|c|c|c|}
\hline \multirow{4}{*}{$\begin{array}{c}\text { Amostras } \\
\text { bruta } \\
\text { tratada } \mathrm{b}\end{array}$} & \multicolumn{3}{|c|}{ Clorofórmio } & \multicolumn{3}{|c|}{ Dibromoclorometano } & \multicolumn{3}{|c|}{ Diclorobromometano } \\
\hline & $\mu \mathrm{g} . \mathrm{L}^{-1}$ & $\mathrm{~A} \times 10^{-6 \mathrm{c}}$ & $\mathrm{dpr}^{\mathrm{d}}$ & $\mu \mathrm{g} . \mathrm{L}^{-1}$ & $\mathrm{~A} \times 10^{-6}$ & $\mathrm{dpr}$ & $\mu \mathrm{g} . \mathrm{L}^{-1}$ & $\mathrm{~A} \times 10^{-6}$ & $\mathrm{dpr}$ \\
\hline & 168 & 2,35 & 2,8 & 4,1 & 0,91 & 3,5 & 25,3 & 4,01 & 3,6 \\
\hline & 84,4 & 1,15 & 9,2 & 2,7 & 0,66 & 7,9 & 17,7 & 2,78 & 9,9 \\
\hline
\end{tabular}

Notas:

a) Nas amostras das cidades de Campinas e São Carlos os teores ficaram abaixo da sensibilidade do DCE.

b) tratada = amostra com $1 \mathrm{gL}^{-1}$ de tiossulfato de sódio, bruta = sem adição tiossulfato de sódio - detalhes no texto.

c) Área média dos picos cromatográficos; injeções em triplicata.

d) Estimativas do desvio padrão relativo, em \%. 
SPME em análises de contaminantes voláteis em águas. Uma avaliação objetiva da qualidade das águas potáveis municipais depende de um acompanhamento temporal de qualidade, como previsto na legislação brasileira ${ }^{8}$. Um acompanhamento sistemático de qualidade de água potável, está em programação, com as considerações sobre recursos para o acompanhamento temporal e amostragem.

\section{REFERÊNCIAS}

1. Arthur, C. L.; Pratt, K.; Motlag, S.; Pawliszyn, J.; J. High Resolut. Chromatogr. 1992, 15, 741.

2. Eisert, R.; Levsen, K.; J. Chromatogr. 1996, 733, 143.

3. Arthur, C. L.; Chai, M.; Pawliszyn, J.; Belardi, R. P.; Pratt, K. F.; Analyst 1993, 351, 1501.
4. Eisert, R.; Levsen, K.; Fresenius J. Anal. Chem. 1995, 351,555

5. Popp, P.; Kalbitz, K.; Oppermann, G.; J. Chromatogr 1994, 638, 133

6. Koester, C. J.; Clement, R. E.; CRC Crit. Rev. Anal. Chem. 1993, 24, 263.

7. Quimby, B. D.; Delaney, M. F.; Uden, P. C.; Barnes, R. M.; Anal. Chem. 1979, 51, 875.

8. Valente, A. L. P.; Pawlyszin, J.; Augusto, F.; Rocha, E. C.; Montero, L; IX Encontro Nacional de Química Analítica; São Carlos, SP, setembro de 1997; Resumo n ${ }^{0}$ 007-0209.

9. Pawliszyn, J.; Solid Phase Microextraction: Theory and Practice; Wiley; New York 1997; p.46.

10. República Federativa do Brasil; Ministério da Saúde; Anexo da Portaria n ${ }^{\text {o. } 36 / G M ; ~} 19$ de Janeiro de 1990. 